\title{
Imagem e autoimagem do artista boêmio
}

João Victor Rossetti Brancato ${ }^{1}$

DOI 10.20396/eha.vil4.3339

Em dezembro de 1926, uma nota em O Jornal anunciava o fim de um tempo:

\begin{abstract}
A boemia literária morreu. Em Paris, como no Rio, ela definitivamente desapareceu. A vida moderna, com a sua febre delirante de conforto, bem-estar, higiene e alegria, matou-a. Para recordá-la, hoje, é preciso reler Murger ou Carrilho. ${ }^{2}$
\end{abstract}

O ano da publicação coincide com as entrevistas de Angyone Costa a diversos artistas, iniciadas em junho n'O Jornal e publicadas depois como livro. A sensação entre alguns dos entrevistados parecia a mesma que a do articulista Peregrino. Perguntado sobre seus hábitos como artista, respondeu o escultor Rodolfo Bernardelli:

- Sóbrio, pautado, metódico. Jamais fiz boemia, como aliás todos os artistas, antes do aparecimento de um livro que reputo - assassino - Vida de Boemia, de Murger. Este livro, só, fez mais vítimas que uma epidemia. Antes deles os artistas não se inutilizavam. Não havia boemia. $^{3}$

O escultor pertencia a uma geração já mais velha e consagrada entre os artistas daquele tempo. Nascido em 1852, estudou na Academia na década de 1870. Já o citado livro de Henri Murger foi publicado em Paris em 1851 sob o título Scènes de la vie de bohème. Durante a formação de Bernardelli talvez o livro ainda não tivesse se popularizado no Rio de Janeiro. Mas nas décadas seguintes expressões como "tipos de Murger" ou "boêmio à Murger" se tornariam recorrentes no vocabulário da época e sugerem a extensão do conhecimento da novela francesa. Bons exemplos advêm do crítico de arte Gonzaga Duque ao falar do passado do pintor Belmiro de Almeida: "Quando solteiro foi um boêmio desregrado, um perfeito tipo à Murger". ${ }^{4}$ Ou ainda ao escrever sobre Heitor Malagutti em 1907 como alguém que "ama com o bandoleirismo dos tipos românticos de Murger".

\footnotetext{
1 Doutorando em História pela Unicamp, sob orientação do Prof. Dr. Jorge Coli e financiamento da FAPESP n 2019/08063-8. Mestre, bacharel e licenciado em História pela UFJF.

2 PEREGRINO. Bohemia literária. OJornal, Rio de Janeiro, ano VIII, nº 2457, 12 dez. 1926.

3 COSTA, João Angyone. A inquietação das abelhas (...). Rio de Janeiro: Pimenta de Mello \& Cia, 1927, p. 29.

4 DUQUE-ESTRADA, Luiz Gonzaga. A arte brasileira. Campinas: Mercado de Letras, 1995, p. 209.

5 Idem. Contemporâneos. Rio de Janeiro: Tipografia Benedito de Souza, 1929, p. 174
} 
Talvez pelo sucesso do livro, Murger fez de seu prefácio uma advertência. Nele, explica o que entende por boemia, um estágio inevitável para os artistas, "o prefácio para a Academia, o hospital

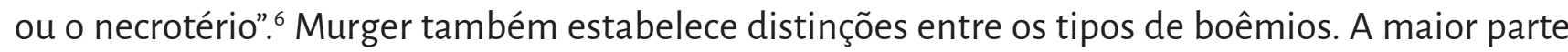
seriam os ignorados, aqueles que viam sua arte como uma fé e não como um ofício, artistas que não conseguiam ou não podiam levar suas obras ao público e que acreditavam que um dia seriam descobertos e aclamados. São esses os que mais se aproximam da noção política de opositores ferrenhos da burguesia.7 Mas "a boemia ignorada não é um caminho", diz Murger, "é um beco sem saída". ${ }^{8}$ A esses ela só pode ser a véspera do hospital ou do necrotério, mas nunca da Academia. A boemia verdadeira, oficial, aquela à qual os personagens de seu livro fazem parte, é o estágio para a Academia. Os boêmios verdadeiros seriam conhecidos por toda a gente, passando seus momentos de dificuldade e privação, mas gozando sua juventude o quanto podiam. Espertos, levavam suas obras ao público, vendiam-nas, sobreviviam. Aspiravam ao sucesso e certamente o alcançariam. ${ }^{9}$

Podemos aproximar o prefácio de Murger a outro dos entrevistados de Angyone: Helios Seelinger, quiçá o mais proeminente boêmio entre os artistas da Primeira República, nascido mais de duas décadas depois de Bernardelli, em 1878. O repórter inicia o texto justificando a boemia juvenil do pintor. "Adolescente no tempo em que era prova de inteligência fazer boemia à maneira de Murger", não pôde "escapar à influência do meio". E ainda: "A mentalidade da época não compreendia que um homem inteligente, fosse um poeta, um escritor ou um artista, deixasse de manifestar o seu talento na mesa do botequim". ${ }^{10}$ Angyone se alinha à opinião de Bernardelli, compreendendo a boemia como um desperdício de talento. Helios, por sua vez, parece grato pela educação recebida por sua tia alemã Elisa:

[...] Quantos rapazes, por falta de freio moral que ela me soube impor, não sucumbiram, ingloriamente, no começo da vida! Uns, o álcool levou, outros não souberam defender-se de moléstias atrozes, ainda outros ficaram para falir, moralmente, na luta áspera da vida. Comigo nada disto aconteceu. Fiz boemia à moda do tempo, mas não sucumbi. ${ }^{11}$

Para Helios Seelinger, a boemia, moda do tempo, foi um estágio, tal qual aquele advertido

\footnotetext{
6 MURGER, Henry. Scènes de la vie de bohème. Paris: Michel Levy Frères Éditeurs, 1872, p. 6, tradução nossa.

7 BLAKE, Nigel; FRASCINA, Francis. As práticas modernas da arte e da modernidade. In: FRASCINA, Francis et al. Modernidade e modernismo: $a$ pintura francesa no século XIX. Cosac Naify, 1998, p. 50; PERROT, Michelle. À margem: solteiros e solitários. In: PERROT, Michelle (org.). História da vida privada 4: da Revolução Francesa à Primeira Cuerra. São Paulo: Companhia das Letras, 1991, pp. 274-275.

8 MURGER, op. cit., p.11, tradução nossa.

9 Ibidem, pp. 6-13. Mais sobre o livro de Murger, cf: CHOTARD, Loïc. La bohème de Murger. In: CHOTARD, Loïc. Approches du XIXe siècle. Paris: Presses Paris Sorbonne, 2000.

10 COSTA, op. cit., p. 158

11 Ibidem, p. 159.
} 
por Murger como a boemia oficial. Porém nos anos 1920 as fontes parecem indicar que, pouco a pouco, esse estágio estava sendo considerado inadequado e a imagem do artista boêmio preterida à do agente laborativo. ${ }^{12}$ As posturas contra os excessos da boemia revelam os imperativos de uma nova sociedade, moderna, racionalizada, eficiente e produtiva, onde a disciplinarização do trabaIho é essencial para a sobrevivência. A boemia seria posta em causa pela necessidade vital da modernidade. ${ }^{13}$

Ainda que a época impusesse um novo ethos para os artistas, refletir sobre a imagem do artista boêmio no período anterior parece uma tarefa bastante fértil, ainda carecendo de investigação profunda sobre o tema. Nas páginas seguintes tentaremos abordar resumidamente a questão a partir de um caso: a representação iconográfica de Helios Seelinger do início de sua carreira até a entrevista com Angyone em 1926. Devido à associação persistente do pintor à vida boêmia, a análise de sua imagem ilustra um bom exemplo para a questão. ${ }^{14}$ Espera-se tecer uma contribuição aos studio studies no Brasil, que tem recebido atenção dos acadêmicos da área, em congressos como Oitocentos: O ateliê do artista, em 2017; o X Seminário do Museu D. João VI/Grupo Entresséculos: o artista em representação e o VI Colóquio Coleções de Arte em Portugal e Brasil nos séculos XIX e XX: coleções de artistas, em 2019; a exposição Trabalho de artista: imagem e autoimagem (1826-1929), organizada na Pinacoteca de São Paulo e no Museu Nacional de Belas Artes, e o dossiê O artista em representação: imagens de artistas através da História da Arte na Revista Modos, ambos também em 2019.

A primeira imagem de Helios Seelinger encontrada é uma caricatura de julho de 1903 na Revista Tagarela por Raul Pederneiras (Figura 1). Ela fora apresentada na seção Poetas e Águias do periódico, que trazia junto do desenho de uma personalidade alguns versos assinados por um tal Biographo. Helios é apresentado como pintor e caricaturista. Porta a caneta, os pinceis e a paleta nas mãos. Os traços elegantes de Raul revelam um corpo atlético, de ombros largos, vestido como um legítimo smart: paletó justo, calças ligeiramente curtas e chapéu-palheta. Corpo e vestuário indicam um homem moderno, elegante e afeito aos esportes, como sugere o halter atrás de Helios. ${ }^{15}$ Ao lado deste, a caneca de cerveja representa os prazeres da vida noturna, a boemia. Levantamento de

\footnotetext{
12 VALLE, Arthur; DAZZI, Camila. Studio studies e fotografias de atelier de pintores brasileiros. AURA. Revista de Historia y Teoría del Arte, n 3 , jun. 2015, p. 43. Disponível online.

13 Cf.: BRANCATO, J.V.R. Imagens de ateliers na crítica de arte de Adalberto Mattos. MODOS. Revista de História da Arte. Campinas, v. 3, n², mai. 2019. Disponível online.

14 Silva abordou a imagem do artista como sátiro. É possível estabelecer associações diretas entre essa imagem e a do boêmio. Cf.: SILVA, Heloisa Maria Seelinger Pereira da. O sol anárquico: reflexões sobre a criação artística e o processo criativo na obra de Helios Seelinger. Rio de Janeiro: UFR]. 15 Cf.: SEVCENKO, Nicolau. A capital irradiante: técnicas, ritmos e ritos do Rio. In: SEVCENKO, Nicolau; NOVAIS, Fernando A. (orgs.) História da vida privada no Brasil-República: da Belle Époque à Era do Rádio. Companhia das Letras, 1998, vol. 3.
} 
peso, levantamento de caneca. Os versos dedicados a Helios retomam sua ascendência alemã e formação em Munique, relacionando-se com a caricatura: "Ya! there is um brasileiro / Que pinta como um alemão / Wergismeinherr [sic], ó companheiro / E manda colaboração (I)". ${ }^{16}$

Em setembro, Helios recebeu o Prêmio de Viagem na Exposição Geral de Belas Artes com a obra Boemia (Figura 2). Em grande formato, retrata uma roda de intelectuais e artistas brasileiros, uma cena comum no imaginário sobre o Rio de Janeiro da Primeira República. Há um croqui do pintor em que estão identificados os personagens. ${ }^{17} \mathrm{O}$ registro permite pensar as redes de sociabilidades do grupo representado, as relações entre as obras e as afinidades afetivas e intelectuais. Assim sendo, é sintomático que Helios se retrate não com os protagonistas - Lucílio de Albuquerque, João Timótheo da Costa e Rodolpho Chambelland, todos pintores -, mas muito discretamente ao fundo, próximo à janela, junto aos caricaturistas Calixto Cordeiro e Raul Pederneiras, como atentou Cardoso. ${ }^{18}$ ]á a caricatura de Raul na Tagarela atesta por outra via a proximidade entre eles.

Boemia é um manifesto, representa uma geração, um modo de vida e um tempo em que isso era possível ou louvável - se tomarmos a sério a relevância de Murger no cenário carioca. O comentário de um articulista anônimo do Jornal do Commercio, tomando o quadro como uma cena de ateliê, captou bem esse espírito boêmio:

Uma das faces peculiares da vida de atelier é a comunicação alegre e amistosa, as relações entre os artistas, os seus amigos e os seus modelos - na permuta ruidosa, sugestiva, prolificadora de impressões e de ideias; aí, no seio desse convívio encantador, é que se passam algumas das horas mais alegres, mais consoladoras da vida artística; dai é que provem muitas vezes o conforto, o levantamento da coragem, a reanimação do espírito e o recrudescimento de fé no futuro, desses desfalecimentos, dessas duras desilusões, dessas lutas fatigantes e acabrunhadoras do artista no esforço doloroso de procurar realizar o seu ideal em uma forma que custa a precisar-se e de ver a sua obra reconhecida em um meio que não quer compreendê-la.

Foi essa vida [ilegível], ruidosa, excitante, cheia de vibrações que Helios Seelinger procurou simbolizar no seu quadro. ${ }^{19}$

A vida excitante entre os pares, o apoio diante das dificuldades da vida artística, as ideias de sofrimento e incompreensão são pontos comuns acerca da vida considerada boêmia, e possuem

\footnotetext{
16 Poetas e Águias: LXX. Revista Tagarela, Rio de Janeiro, $\mathrm{n}^{\circ} 108,30$ jul. 1903, p. $5 . \mathrm{O}$ autor do texto solicitava a Helios suas caricaturas para a revista, que as enviava ao menos desde o ano anterior, como atestam as edições 32 e 33, de 1902.

17 NETO, Américo Conçalves. Seelinger, um pintor da nossa “Belle Époque”. Boletim do Museu Nacional de Belas Artes. Rio de Janeiro. MNBA, ano

7, 1988, p.27-29; VALLE, Arthur. Helios Seelinger, um pintor "salteado". 19\&20, Rio de Janeiro, v. I, nº 1, mai. 2006. Disponível online.

18 DENIS, Rafael Cardoso. A arte brasileira em 25 quadros (1790-1930). Rio de Janeiro: Record, 2008 , p. 138.

19 NOTAS de Arte. Jornal do Commercio, Rio de Janeiro, 9 set. 1903, p. 3. Disponível online.
} 


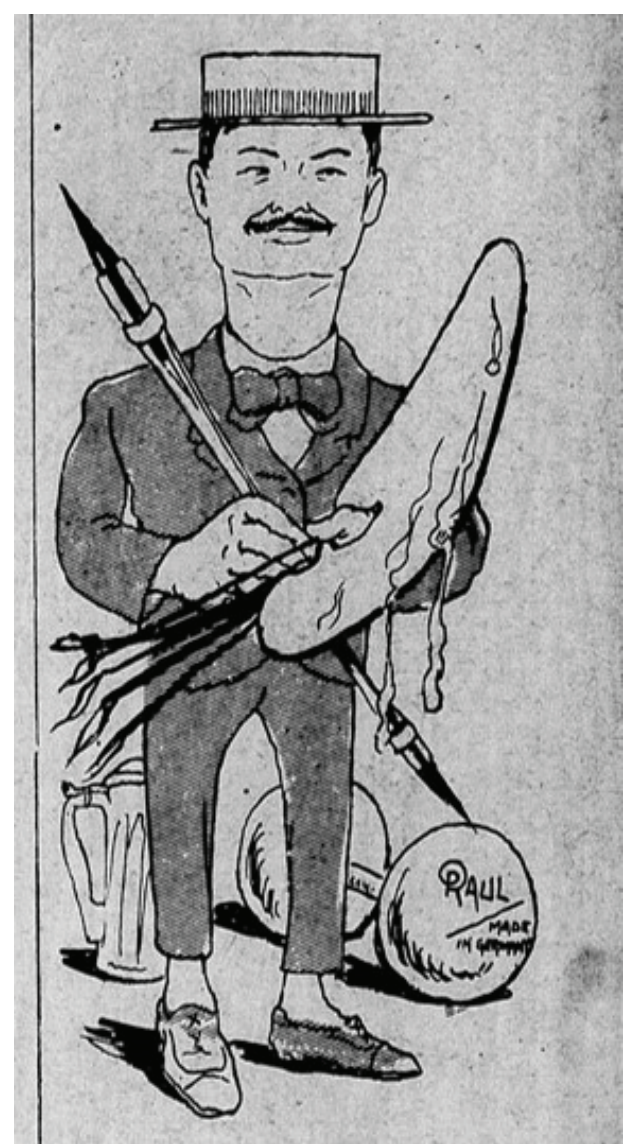

[Figura 01] Raul Pederneiras. Helios Seelinger. 1903.

Revista Tagarela, Rio de Janeiro, $n^{\circ} 108,30$ jul. 1903, p. 5.

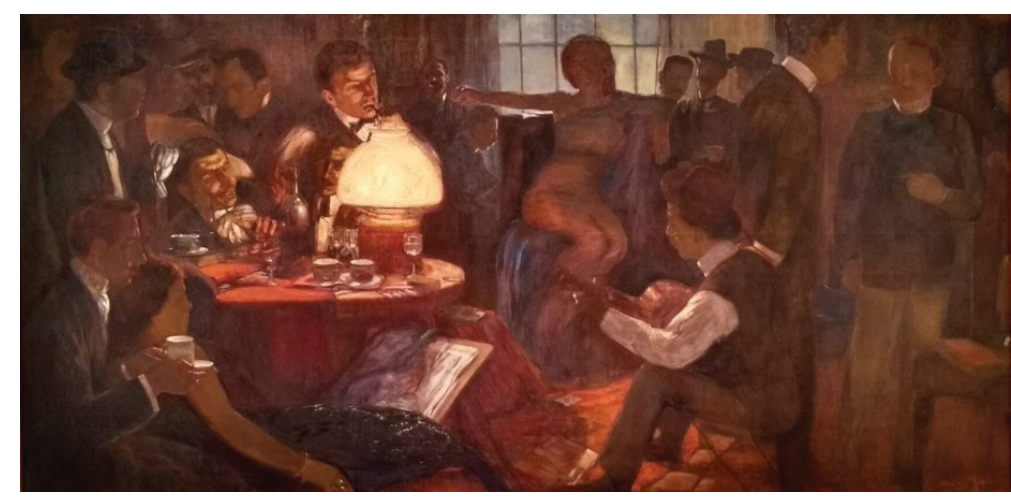

[Figura 02] Helios Seelinger. Boemia. 1903.

Óleo sobre tela, 103 × 189,5 cm. Museu Nacional de Belas Artes, R].

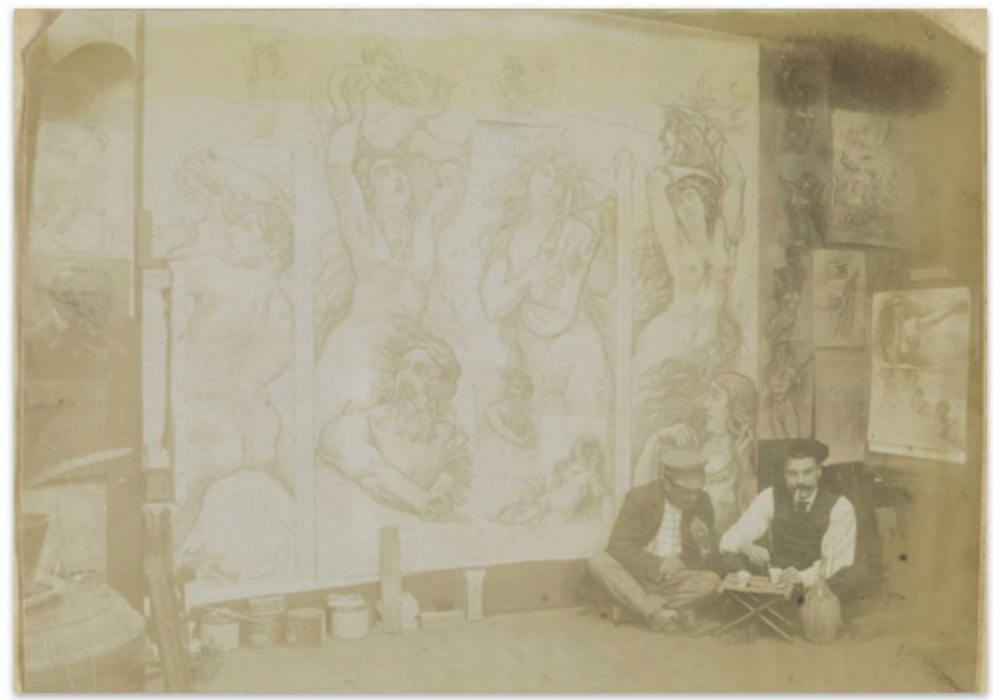

[Figura 03]

Um canto do atelier em Paris, de Helios Seelinger. Fotografia $p \& b$. Álbum de fotografias de artistas brasileiros e estrangeiros, de M. Nogueira da Silva. Fundação Biblioteca Nacional, R].

\section{[Figura 04]}

Carlos Chambelland.

Retrato de Helios Seelinger. 1910 c.

Óleo sobre tela, $44 \times 45 \mathrm{~cm}$. Coleção privada. 
eco, mais uma vez, no livro de Murger. Junte-se a isso os próprios elementos presentes na tela: o álcool, o cigarro, o jogo, a noite e a música, além da presença alegórica da Boemia - La Bohème, escreveu Helios, tal como a ópera, inspirada em Murger.

Após o aproveitamento do prêmio, estudando por dois anos em Paris, Helios retornaria à Europa em algumas ocasiões. Em 1910, por exemplo, dividiu ateliê com Arthur Timótheo da Costa na capital francesa. ${ }^{20}$ Uma fotografia de ambos no álbum do crítico Nogueira da Silva permite outras apreensões da boemia (Figura 3). Em primeiro plano, os dois pintores no ateliê, sentados, com trajes menos formais e boinas. Um fuma um cachimbo, o outro um cigarro, e Helios parece misturar algo em um copo ao lado de uma garrafa de conteúdo duvidoso. A legenda, provavelmente redigida pelo próprio crítico, explica com bom humor a situação: "Um canto do atelier, em Paris, de Helios Seelinger-À direita, Arthur Timótheo, pint. e Helios Seelinger, pint., tomam uma droga qualquer". No álbum inexistem fotografias ou legendas contendo situações semelhantes, tornando o caso excepcional. Considerando que a foto deve ter sido enviada por um dos artistas a Nogueira, torna-se uma imagem que deseja ser vista, ainda que em um circuito privado.

É provável que também seja dessa época um retrato de Helios feito por Carlos Chambelland (Figura 4). Tal como Timótheo, o pintor esteve em Paris nos idos de 1910. No verso do retrato, a filha de Helios, Elisa (como a tia), registrou que a obra foi feita por Chambelland em Paris. ${ }^{21} \mathrm{~A}$ boina com que Helios é representado se assemelha àquela da fotografia anterior, típica do imaginário boêmio de Montmartre ainda hoje. Os trajes não revelam nada demais, mas sua fisionomia diz bastante. $\mathrm{O}$ rubor de seu rosto, o bigode espevitado e os olhos curiosos indicam uma postura travessa e juvenil, ainda que Helios tivesse então cerca de trinta anos e seus cabelos começassem a escassear. A obra em questão pode não depreender por si só uma postura boêmia, mas a irreverência contida entre artista e modelo é muito própria aos ambientes boêmios que sabemos que participavam.

A título de comparação, o pintor Lucílio de Albuquerque, chegado em Paris em 1907, fez um autorretrato em nanquim e enviou-o para Gonzaga Duque (Figura 5). Ele denota uma outra imagem da boemia, mais comum que a do retrato de Chambelland. É a do artista solitário, em meio a uma aura obscura, soturna, que expressa um distanciamento do mundo. Murger novamente parece ter eco aqui na ideia do boêmio incompreendido, sofredor. Já a boemia de Helios é a boemia alegre, "ruidosa, excitante". Ela se relaciona à festa, aos bailes, ao carnaval. Não por acaso o artista partici-

\footnotetext{
20 VALLE, Arthur; DAZZI, Camila. Ateliês de artistas brasileiros em Paris através da fotografia. Revista de História da Arte e Arqueologia, Campinas, $\mathrm{n}^{\circ} 23,2015$, p. 10. 21 SORAIA Cals Escritório de Arte; Marcela Cals Leiloeira. Leilão Abril de 2019 (Catálogo). São Paulo: abr. 2019, p. 53.
} 


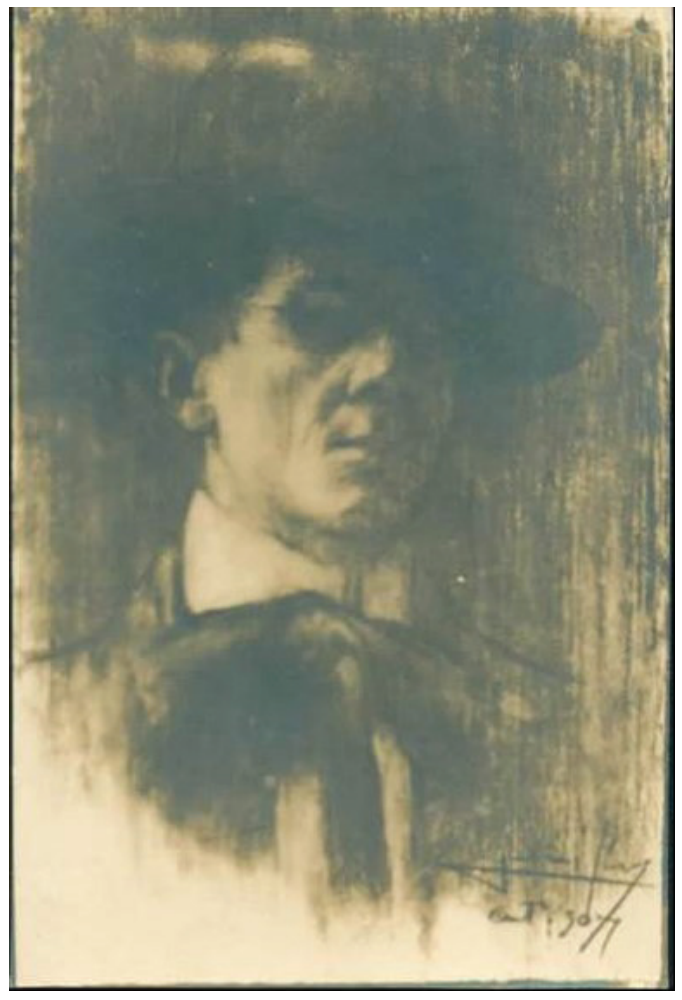

[Figura 05] Lucílio de Albuquerque. Autorretrato. 1907. Nanquim sobre papel. Coleção Gonzaga Duque, Fundação Casa Rui Barbosa, R].

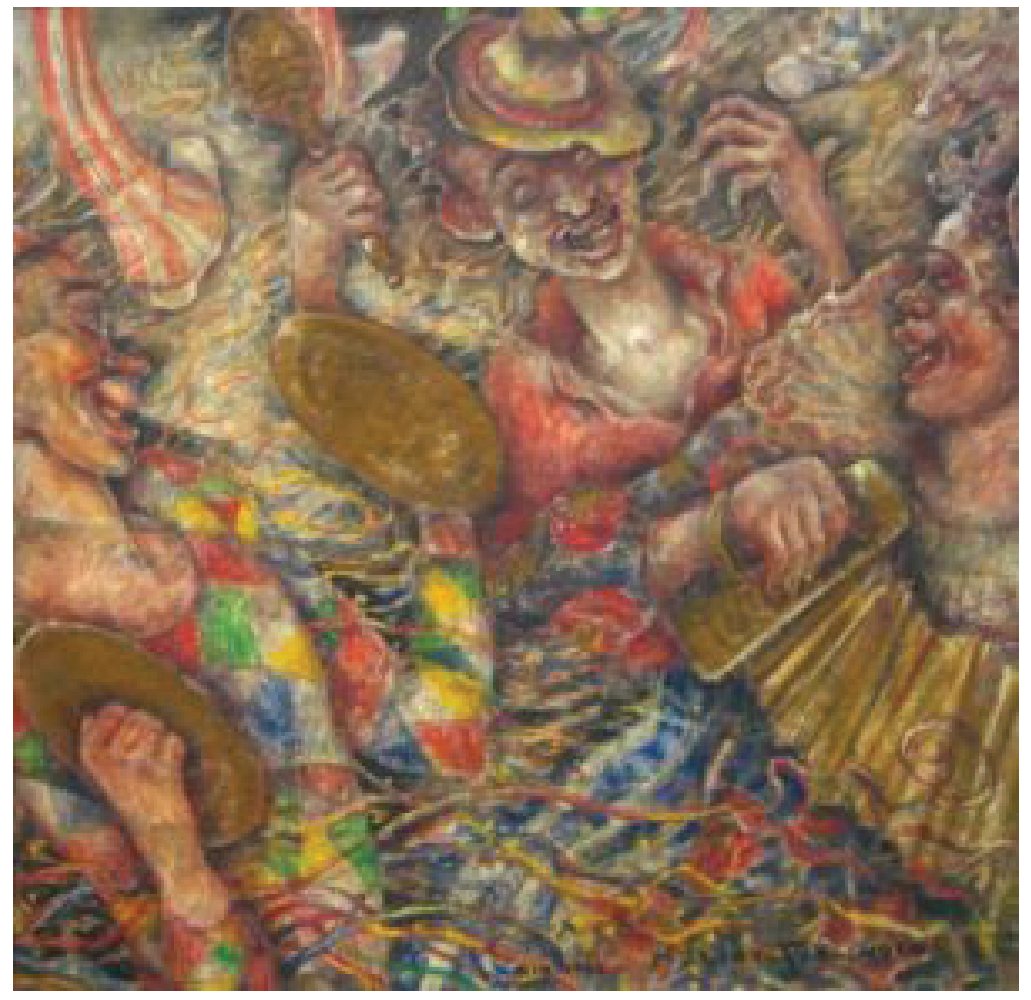

[Figura 06] Helios Seelinger. Carnaval na rua - farra na Praça Onze, 1945. Óleo sobre tela, 70,5 × 70,5 cm. Pinacoteca do Estado de São Paulo, SP.

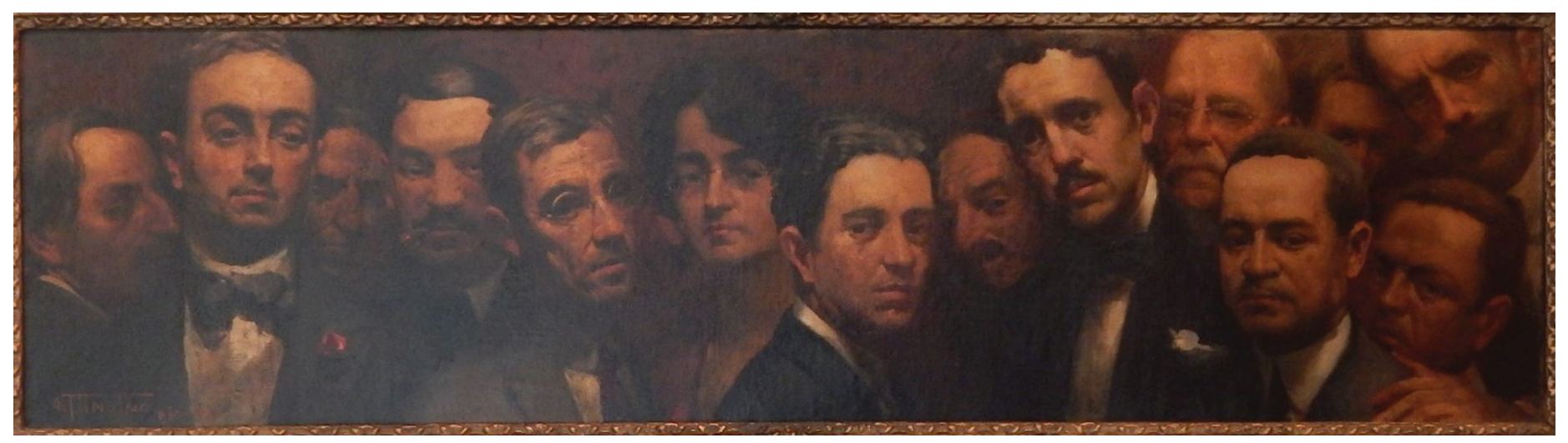

[Figura 07] Arthur Timótheo da Costa. Alguns colegas. 1921.

Óleo sobre tela, 45,5 ×170,6 cm. Museu Nacional de Belas Artes, R]. 
pou desde bem cedo desses festejos, conforme já demonstrou Valle, fosse no Lumpen Fest de Munique em 1896, no Bal des Quat'z'Arts de Paris em 1913, ou na versão brasileira do Baile dos Artistas no Rio de Janeiro em 1918, criado pelo próprio Helios. ${ }^{22}$ Além disso, ainda produziu desenhos e pinturas sobre o tema ao longo de sua vida, como Carnaval na rua - farra na Praça Onze (Figura 6).

Por fim, Arthur Timótheo da Costa expôs em 1921 a obra Alguns colegas (Figura 7), um retrato coletivo de artistas, hoje quase todos identificados. ${ }^{23}$ Helios é o quarto, reconhecível pelos característicos olhos amendoados. É o único a fumar na cena, a centelha de brasa na ponta do charuto atrai o olhar para si. Sua expressão revela algo de blasé e enfadonho, um olhar que ao mesmo tempo encara o espectador e parece desinteressado, agora na casa dos quarenta de idade. Assim como Chambelland atribui certa singularidade a Helios quando o pinta, Timótheo faz o mesmo ao representá-lo junto aos demais. Em um tempo onde consumo de tabaco era comum e elegante, decerto Helios não deveria ser o único do grupo a fumar. ${ }^{24}$ Então por que é justo ele e só ele o apresentado com o charuto, senão por um desejo de vinculá-lo ao mundo dos prazeres e da boemia? Helios era o único entre os sisudos colegas que parecia autorizado, por sua irreverência, a praticar a ação na cena. E assim Arthur Timótheo o fez, distinguindo-o dos demais.

Concluindo, é sempre possível pensar o quanto a imagem de um artista é real ou construção intencional, mas um aspecto quiçá mais relevante é a forma como o público o percebe e avalia tendo em vista essa imagem. No que tange a representação de Helios Seelinger no Brasil, o artista obteve sucesso, e parece ter sido recebido sempre positivamente pelos jornais e revistas, senão por sua obra, ao menos por sua personalidade e carisma. Em nosso limitado recorte cronológico, procuramos demonstrar o quanto a sua imagem, criada e perpetuada por si e por outros, manteve estreitas relações com a boemia nos tempos áureos da Belle Époque carioca. Embora nem sempre essa associação pareça imediata, a insistente vinculação de Helios a certos atributos - o álcool, o tabaco, as drogas, as festas - garantiram a perpetuação bem-sucedida dessa imagem.

\footnotetext{
22 VALLE, Arthur. Sociabilidade, boêmia e carnaval em ateliês de artistas brasileiros em fins do século XIX e início do XX. In: VALLE, Arthur et al. (orgs.) Oitocentos - Tomo IV: O ateliê do artista. Rio de Janeiro: CEFET/R], 2017, pp. 51-55.

23 COMES, Natália Cristina de Aquino. Retrato de artista no ateliê: a representação de pintores e escultores pelos pincéis de seus contemporâneos no Brasil (1878-1919). Guarulhos: UNIFESP, 2019, pp. 200-203; CHRISTO, M.C.V. Retratos de grupos de artistas no Brasil: as obras de Arthur Timótheo da Costa e Angelo Bigi. MODOS. Revista de História da Arte. Campinas, vol. 3, nº 2, mai. 2019. Disponível online. 24 SEVCENKO, op. cit., pp. 528-529.
} 


\section{Referências Bibliográficas:}

FRASCINA, Francis et al. Modernidade e modernismo: a pintura francesa no século XIX. Cosac Naify, 1998.

BRANCATO, J.V.R. Imagens de ateliers na crítica de arte de Adalberto Mattos. MODOS. Revista de História da Arte. Campinas, v. 3, $n^{\circ} 2$, mai. 2019. Disponível online.

CHOTARD, Loïc. La bohème de Murger. In: CHOTARD, Loïc. Approches du XIXe siècle. Paris: Presses Paris Sorbonne, 2000.

CHRISTO, M.C.V. Retratos de grupos de artistas no Brasil: as obras de Arthur Timótheo da Costa e Angelo Bigi. MODOS. Revista de História da Arte. Campinas, vol. 3, nº 2, mai. 2019 Disponível online.

DENIS, Rafael Cardoso. A arte brasileira em 25 quadros (1790-1930). Rio de Janeiro: Record, 2008.

COMES, Natália Cristina de Aquino. Retrato de artista no ateliê: a representação de pintores e escultores pelos pincéis de seus contemporâneos no Brasil (1878-1919). Guarulhos: UNIFESP, 2019 (Dissertação de Mestrado em História da Arte).

NETO, Américo Conçalves. Seelinger, um pintor da nossa "Belle Époque". Boletim do Museu Nacional de Belas Artes, Rio de Janeiro. MNBA, ano 7, 1988.

PERROT, Michelle (org.). História da vida privada 4: da Revolução Francesa à Primeira Cuerra. São Paulo: Companhia das Letras, 1991.

SEVCENKO, Nicolau; NOVAIS, Fernando A. (orgs.) História da vida privada no Brasil -República: da Belle Époque à Era do Rádio. Companhia das Letras, 1998, vol. 3.

SILVA, Heloisa Maria Seelinger Pereira da. O sol anárquico: reflexões sobre a criação artística e o processo criativo na obra de Helios Seelinger. Rio de Janeiro: UFR], 2003 (Dissertação de Mestrado em Psicologia).

SORAIA Cals Escritório de Arte; Marcela Cals Leiloeira. Leilão Abril de 2019 (Catálogo). São Paulo: abr. 2019.

VALLE, Arthur. Sociabilidade, boêmia e carnaval em ateliês de artistas brasileiros em fins do século XIX e início do XX. In: VALLE, Arthur et al. (orgs.) Oitocentos-Tomo IV: O ateliê do artista. Rio de Janeiro: CEFET/RJ, 2017.

VALLE, Arthur. Helios Seelinger, um pintor "salteado". 19820, Rio de Janeiro, v. I, nº 1, mai. 2006. Disponível online.

VALLE, Arthur; DAZZI, Camila. Studio studies e fotografias de atelier de pintores brasileiros. AURA. Revista de Historia y Teoría del Arte, $n^{\circ}$ 3, jun. 2015. Disponível online.

VALLE, Arthur; DAZZI, Camila. Ateliês de artistas brasileiros em Paris através da fotografia. Revista de História da Arte e Arqueologia, Campinas, $\mathrm{n}^{0}$ 23, 2015. 